\title{
Developing Design of Mobile Robot Navigation System Based on Android
}

\author{
Sigit Yatmono, Muhfizaturrahmah \\ Electrical engineering education department \\ Faculty of engineering, UNY \\ Yogyakarta, Indonesia \\ s_yatmono@uny.ac.id, muhfizaturrahmah@uny.ac.id
}

\begin{abstract}
Navigation system of the mobile robot movement is a basic problem of a mobile robot control system. We must be able to establish and control the movement of the mobile robot fit with what we want and can avoid obstacles or barriers that hinder direction of motion of the mobile robot. In this study attempted to develop a mobile robot navigation system using Bluetooth and Android smartphone. Android GUI system was developed using the facilities of online programming through site remotexy.com. Robots were developed based on Arduino UNO, 2 de motors with L298N driver and HC05 Bluetooth communication system. Results from the trial showed that the GUI navigation system can be work properly control mobile robot movement and the range of a Bluetooth-based control reaches a maximum distance of 10.5 meters.
\end{abstract}

Keywords-mobile robot, android, Bluetooth, arduino

\section{INTRODUCTION}

Navigation system of the mobile robot movement is a basic problem of a mobile robot control system. We must be able to establish and control the movement of the mobile robot fit with what we want and can avoid obstacles or barriers that hinder direction of motion of the mobile robot.

According to Maxim A Batalin [1] stated that the issue in mobile robot navigation systems is classified in two term: local navigation which is only a few centimeters from the mobile robot and global navigation, which means a wider area in which the mobile robot can not observe the final destination of the robot movement's end points .Mobile Robot's movement control system still use infrared as a line sensor and ultrasonic sensors. There is a navigation system that already uses the robot's ability to identify and determine the position of the robot autonomously using GPS technology. In this case the mobile robot is moving on a route based on the coordinates of which have been determined, but if there are obstacles or things that can affect the movement of the robot, the robot can not handle it unless in the body of robot included multiple sensors and camera system to send an status of route condition, the movement of the robot can not be flexible according to what we want. For that we need a navigation control system of a mobile robot that can be interactive and flexible without sensors that allow the robot to move according to control user.
Technological developments android smartphones increasingly advanced. Smartphone not only serves as a communication tool but with the addition of Android-based applications we can use android smartphone as a controlling device system.

The navigation system uses the existing android app still mostly in the form of buttons, which is to change the direction of our movement must press the button on the smartphone screen. This is done by Ritika Pahuja [5] using the Bluetooth RC controller application that just using the directional buttons without accelerometer sensor as shown in Figure 1

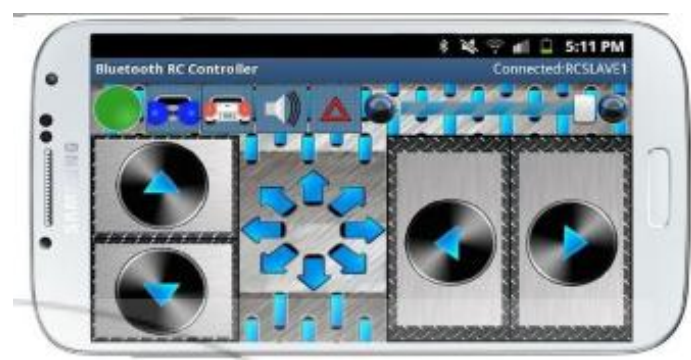

Fig. 1. Bluetooth RC controller

While Iwan Fitrianto Rahmat [2] did the same thing but with a bit difference that developing application Bluetooth $\mathrm{RC}$ controller by adding accelerometer sensor, although to activate it must still needs to pressed the button then smartphone driven in the direction of the desired robot's movement. The navigation system that is attempting to build in this study is using a self-designed applications with help of remoteXY.com sites that will generate android application which can be immediately implemented in the Arduino codes so it's making more flexible in the display settings and programs.

\section{METHOD}

Application development in this paper uses the method of research and development (Pressman: 2002) [6]. The stages that must be passed are:

(a). The analysis stage to identify and obtain data about the needs of what is required in the design and implementation 
of systems and the next design process. (b). Design is the stage did some thinking to get the most effective and efficient way to implement the system with the aid of the data obtained in the analysis phase. (c). Implementation is the stage translate the design into the form of GUI user interface applications and settings android mobile robot motion using remoteXY application. (d) Testing conducted to determine whether the system has been made in accordance with the results of the needs analysis. Tests conducted consists of two parts, hardware testing and software testing.

The design of software and hardware can be described in the block diagram as follows:

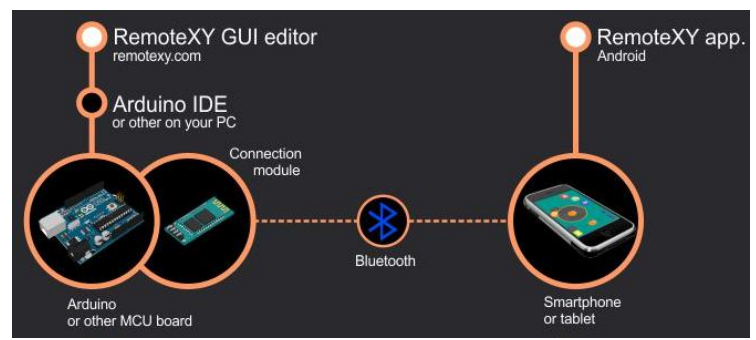

Fig. 2. System block diagram

The system that developed consists of two parts, first is arduino robot and second is robot navigation system based on remoteXY app. Developing application user interface GUI remoteXY made through the editor in remoteXY.com then the design is downloaded as the arduino code. This program code that will be read by remotexy android application.

Algorithms of remotexy navigation system that develope shown in the following flowchart:

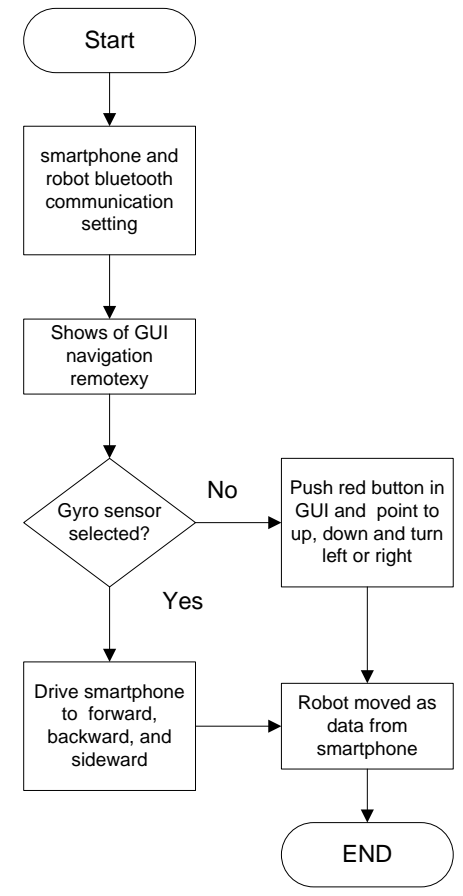

Fig. 3. Flowchart system

\section{RESULT AND DISCUSSION}

Results of the design robot in this paper as shown below:

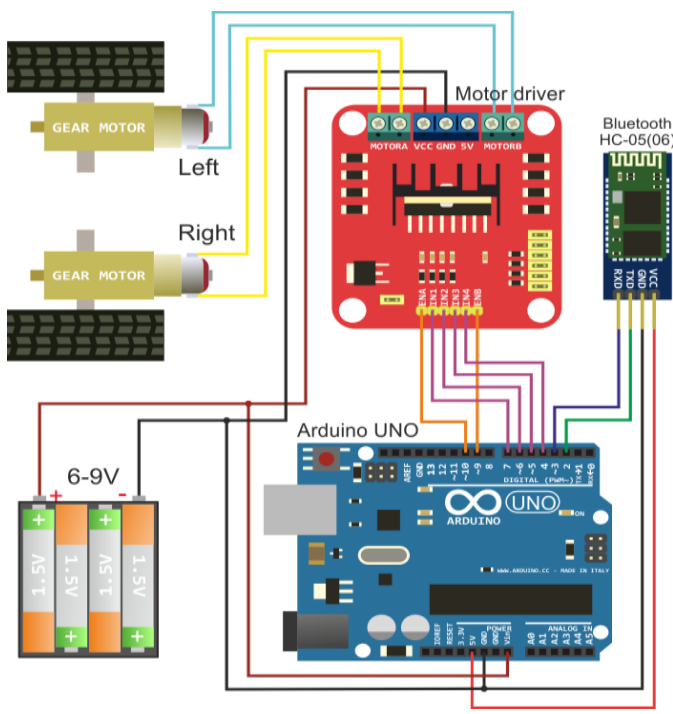

Fig. 4. Wiring diagram of robot

While the results of the design of mobile robot navigation software GUI that developed shown as in Figure 5 below:

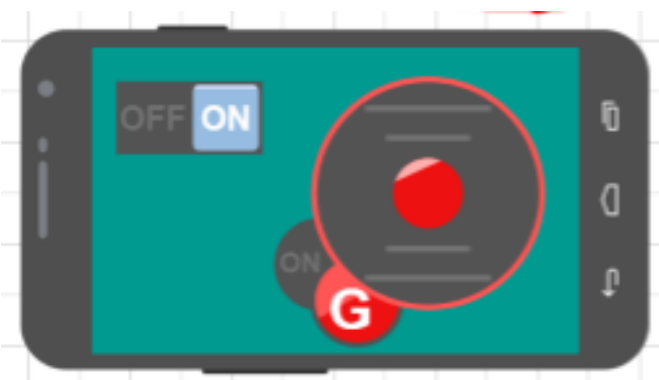

Fig. 5. GUI navigation

Tests conducted to determine whether the system has been made in accordance with the results of the needs analysis. Tests conducted consists of two parts, hardware testing and software testing using Black box testing method.

Tests were conducted to determine the success of the design of the hardware and software are developed, the test carried out on GUI navigation system designed compared to the suitability of the robot movement. Observational data are shown in Table 1.

Based on Table 1. it can be stated that the navigation system is working properly and in accordance with the movement of the robot. When first turned on, the software will display a remotexy initial setting that contains the activation of Bluetooth and the Bluetooth pairing process between a Bluetooth on smartphone with bluetooth on robot, as in Figure 6. 


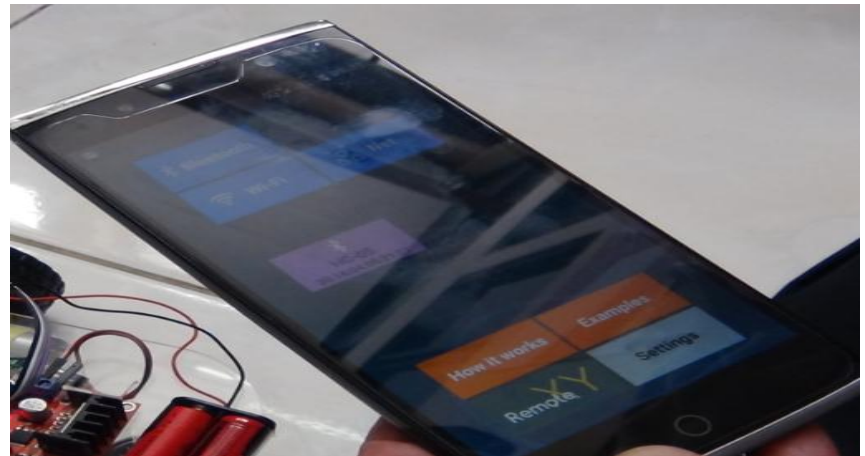

Fig. 6. Initialization look of GUI application

After a successful connection between the Bluetooth on the smartphone and the mobile robot (the pairing process) then the smartphone screen will display the navigation screen. This display is the result of translation remoteXY apk based on application program code that is sent by arduino which placed on robot. Arduino module that installed in the mobile robot contains the $\mathrm{C}$ code that includes translation of GUI navigation on android smartphone and code of robot motion control in accordance with the robot's wiring diagram on designed mobile robot.

Display GUI navigation robot that successfully transmitted by the module Arduino on robot via Bluetooth communication shown in Figure 7. In this figure indicates that the GUI displayed on the smartphone is same with GUI that designed in remotexy.com site. When the Gyro sensor is selected and activated, with just move the smartphone then the robot will move in the same direction of movement of the smartphone. This happens because when the smartphone moves, the coordinates $\mathrm{x}, \mathrm{y}$ and $\mathrm{z}$ of the smartphone changes. This data change will be sent to the mobile robot via Bluetooth and data coordinate will be read and sent to the motor driver L298N to activate the DC motor corresponding to motion desired.

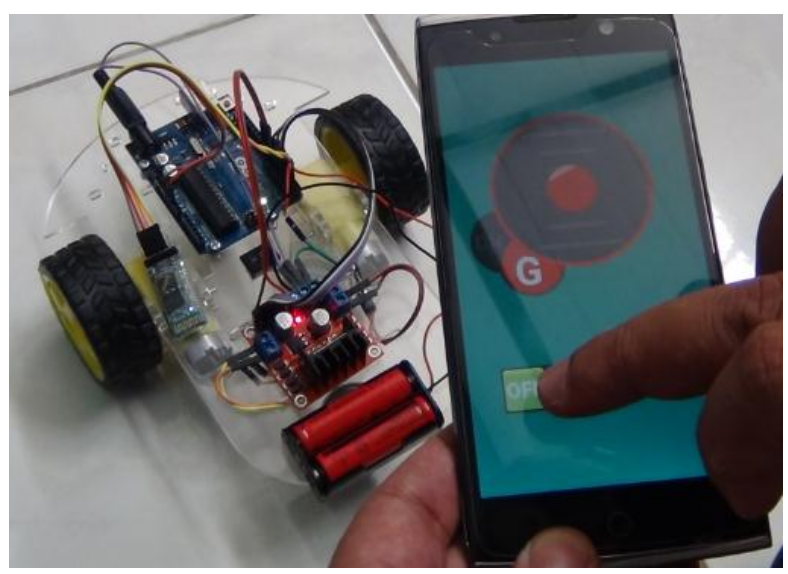

Fig. 7. Display GUI navigation after pairing process

When the manual button is selected, the robot movements will be controlled manually by the movement of the red button. When we press and drag the red button then shifted towards to the top, bottom, right and left to move the robot. To stop the movement of the robot is done by putting the red button back on the middle position. In testing the mobile robot movement data obtained furthest distance that can still be done setting the direction of movement of robots with a value of maximum distance of $10.5 \mathrm{~m}$.

TABLE I.

\begin{tabular}{|l|l|l|l|}
\hline No & $\begin{array}{c}\text { Button of } \\
\text { navigation }\end{array}$ & \multicolumn{1}{|c|}{ Function } & \multicolumn{1}{|c|}{$\begin{array}{c}\text { Robot movement } \\
\text { result }\end{array}$} \\
\hline 2 & G & $\begin{array}{l}\text { Navigation system } \\
\text { activation }\end{array}$ & $\begin{array}{l}\text { Navigation buttons can } \\
\text { serve to activate the } \\
\text { navigation system }\end{array}$ \\
\hline 3 & $\begin{array}{l}\text { Gyro } \\
\text { activation }\end{array}$ & $\begin{array}{l}\text { Control robot } \\
\text { manually }\end{array}$ & $\begin{array}{l}\text { The robot can move } \\
\text { based on the direction of } \\
\text { movement of the } \\
\text { smartphone }\end{array}$ \\
\hline $\begin{array}{l}\text { The robot moves in the } \\
\text { direction of the red dots } \\
\text { are pressed then } \\
\text { directed manually } \\
\text { towards the top, bottom, } \\
\text { right and left side }\end{array}$ \\
\hline
\end{tabular}

\section{CONCLUSION}

Based on the results of the design and testing of mobile robot navigation system that developed, it can be concluded as follows:

1. Hardware robotic navigation system consists of a robot-based arduino by using $2 \mathrm{dc}$ motors and motor driver L298N, as well as software that provides translation arduino GUI navigation remotexy.com made on site as well as setting the appropriate input $\mathrm{dc}$ motor movement sensor is sent via Bluetooth. Software applications used on smartphones is remotexy application is downloaded for free on google play store.

2. The performance of the hardware and software developed has been successfully performed well and as planned.

3. The farthest distance control uses Bluetooth communication is done is as far as $10.5 \mathrm{~m}$.

\section{REFERENCES}

[1] Batalin, Maxim A, Mobile Robot Navigation using a Sensor Network, IEEE International Conference on Robotics and Automation, 636642, 2004

[2] Iwan Fitrianto R, Navigasi Mobil Robot RC Berbasis Aplikasi Android, academia.edu, 2014

[3] Jogiyanto, HM.. Analisis \& Disain Sistem Informasi: Pendekatan Terstruktur Teori dan Praktek Aplikasi Bisnis. Yogyakarta : Andi, 1989

[4] Kimmo and Terro K, Make: Arduino bots and gadgets, O'Reilly Media Inc. 2011

[5] Pahuja, Ritika, Android Mobile Phone Controlled Bluetooth Robo Using 8051 Microcontroller, International Journal of Scientific Engineering and Research (IJSER), 2014

[6] Pressman, Roger S., "Rekayasa Perangkat Lunak: pendekatan praktis (Buku 1)", Andi, Yogyakarta, 2002. 